\title{
Nature of deep center emissions in GaN
}

\author{
A. Sedhain, J. Li, J. Y. Lin, and H. X. Jiang ${ }^{\text {a) }}$ \\ Department of Electrical and Computer Engineering, Texas Tech University Lubbock, Texas 79409, USA
}

(Received 20 December 2009; accepted 23 March 2010; published online 12 April 2010)

Photoluminescence (PL) emission spectroscopy was employed to probe the nature of deep center emissions in GaN. The room temperature PL spectrum measured in the infrared (IR) region revealed an emission band centered around $1.23 \mathrm{eV}$. Based on detailed analysis of both the IR and visible emission spectra, we suggest that this emission band is a band-to-impurity transition involving a deep level complex consisting of a gallium vacancy and an oxygen atom sitting on one of the neighboring nitrogen sites; the $\left(\mathrm{V}_{\mathrm{Ga}}-\mathrm{O}_{\mathrm{N}}\right)^{2-}$ charge state of $\left(\mathrm{V}_{\mathrm{Ga}}-\mathrm{O}_{\mathrm{N}}\right)^{2-11-}$. Two electronic structures, which arise due to two different configurations of $\left(\mathrm{V}_{\mathrm{Ga}^{-}}-\mathrm{O}_{\mathrm{N}}\right)^{2-11-}$, with $\mathrm{O}_{\mathrm{N}}$ either along the c-axis (axial configuration) or in one of the three equivalent tetrahedral positions (basal configuration), were observed. Our result also provides explicit evidence that both the yellow luminescence band and the $1.23 \mathrm{eV}$ emission line in $\mathrm{GaN}$ are related to a common deep center, which is believed to be $\left(\mathrm{V}_{\mathrm{Ga}}-\mathrm{O}_{\mathrm{N}}\right)^{2-11-}$. (C) 2010 American Institute of Physics. [doi:10.1063/1.3389497]

GaN materials are progressively becoming the most appropriate candidate for next generation lighting and other optoelectronic and electronic applications. The efficiency of GaN-based light-emitting diodes (LEDs) has been greatly improved and the GaN-based blue-violet laser with a lasing wavelength $\sim 405 \mathrm{~nm}$ has already revolutionized optical data storage and readout capacity. Understanding the electronic and optical properties of $\mathrm{GaN}$ is imperative for improving the performance of GaN-based devices and for understanding the properties of $\mathrm{InGaN}$ and AlGaN ternary alloys, which have emerged as important semiconductor materials for applications in a wide spectral range-from infrared (IR) to deep ultraviolet.

There have been many reports on the structural, electrical, and optical properties of GaN materials and devices over the past two decades. ${ }^{1-6}$ Studies on optical properties are mainly confined to band-edge emission and impurity bands in the visible spectral region. Among the impurity bands investigated, the yellow luminescence (YL) band in intentionally or unintentionally doped n-GaN is, by far, the most extensively studied. This band is believed to be a donoracceptor-pair (DAP) type transition from a shallow donor to a deep acceptor. However, there are still controversies regarding the nature of the deep acceptor involved. Some of the earlier reports suggest the involvement of silicon on gallium site $\left(\mathrm{Si}_{\mathrm{Ga}}\right)$ while others discussed possible involvement of carbon on nitrogen site $\left(\mathrm{C}_{\mathrm{N}}\right)^{7,8}$ Based on the first principal calculations, positron annihilation, and doping experiments, it is now widely accepted that the deep acceptor is a complex consisting of a gallium vacancy and a nearest neighbor donor, namely an oxygen atom sitting on one of the neighboring nitrogen sites $\left(\mathrm{V}_{\mathrm{Ga}}-\mathrm{O}_{\mathrm{N}}\right)^{2-11-8-16}$ Additionally, deep levels around $1.2 \mathrm{eV}$ were previously observed in different experiments ${ }^{17-19}$ in $\mathrm{n}$-GaN. A few other reports discussed a roughly $1.27 \mathrm{eV}$ peak that was observed due to the involvement of $\mathrm{Mn}^{6,20}$ However, the physical origin of the $1.23 \mathrm{eV}$ emission and its possible connection with the YL band is not clear. In this letter, we report on the observation of an emis-

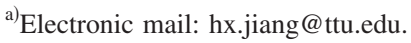

sion line in the IR region $(\sim 1.23 \mathrm{eV})$ in GaN. Its physical mechanism and connection with the YL band is discussed.

GaN epilayers were grown on c-plane (0001) sapphire substrate by metal organic chemical vapor deposition (MOCVD). High crystalline quality of the material was confirmed with a narrow linewidth of (002) rocking curve from x-ray diffraction (300 arc sec). Hall measurements showed that the sample was n-type with a background electron concentration of $7 \times 10^{16} \mathrm{~cm}^{-3}$ and mobility of $650 \mathrm{~cm}^{2} / \mathrm{V} \mathrm{s}$. Atomic force microscopy revealed an atomically flat surface morphology with a roughness of $0.6 \mathrm{~nm}$. Photoluminescence (PL) spectra were measured by exciting with a femtosecond laser, photon energy set at $\sim 4.74 \mathrm{eV}$, which is a frequency tripled Ti-sapphire laser with a $76 \mathrm{MHz}$ repetition rate. ${ }^{21}$

The room temperature PL spectrum measured in the IR region is plotted in Fig. 1(a) from 0.9 to $1.5 \mathrm{eV}$. We observed a broad emission band with a peak at $1.23 \mathrm{eV}$. The emission peak energy is very close to values previously calculated by

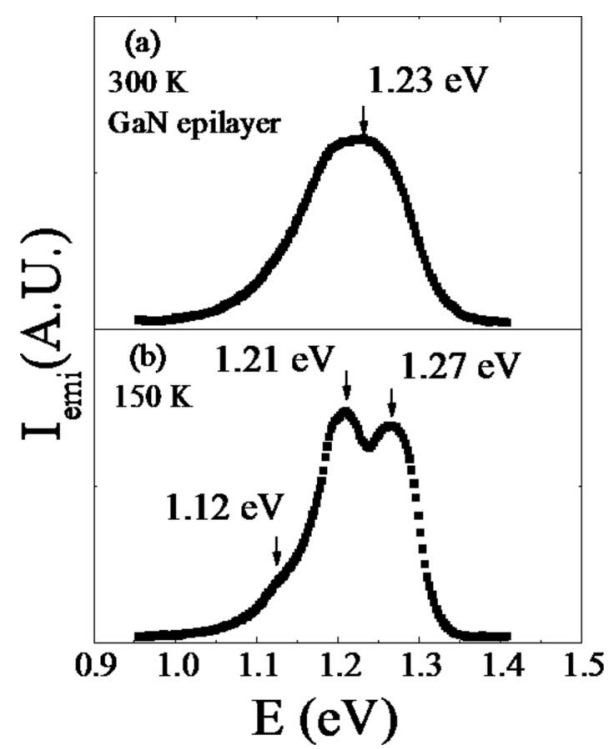

FIG. 1. (a) $300 \mathrm{~K}$ and (b) $150 \mathrm{~K}$ PL spectra of unintentionally doped n-GaN epilayer in the IR spectral region. 

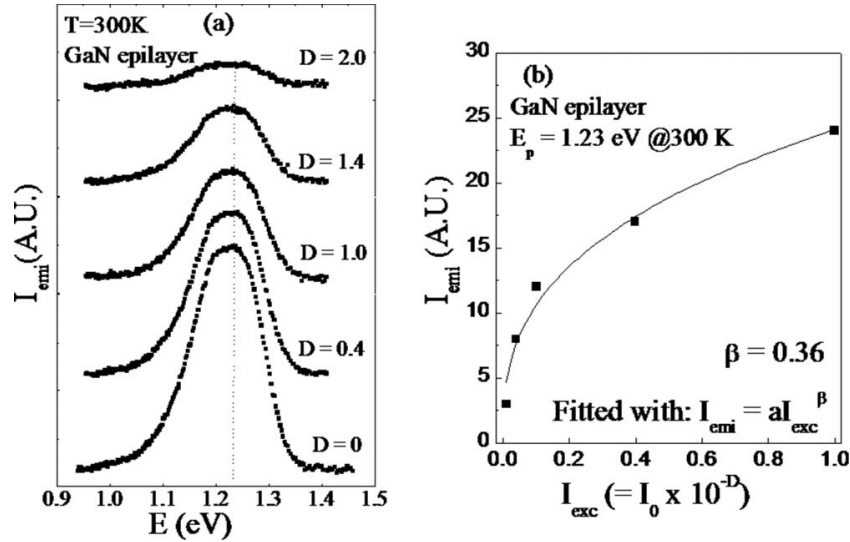

FIG. 2. (a) Excitation intensity $\left(\mathrm{I}_{\text {exc }}\right)$ dependent PL spectra of GaN around $1.23 \mathrm{eV}$ at $300 \mathrm{~K}$ and (b) PL emission intensity $\left(\mathrm{I}_{\mathrm{emi}}\right)$ as a function of $\mathrm{I}_{\text {exc }}$ (solid squares) and least-squares fit of data with $\mathrm{I}_{\mathrm{emi}}=\mathrm{aI}_{\mathrm{exc}}^{\beta}$ (solid line).

Neugebauer and Van de walle (1.1 eV) (Ref. 22) and Reynolds et al. $(1.3 \mathrm{eV})$ (Ref. 23) for the electronic level of the gallium vacancy complex $\left(\mathrm{V}_{\mathrm{Ga}}-\mathrm{O}_{\mathrm{N}}\right)^{2-/ 1-}$ with respect to the top of the valence band (VB). The PL spectrum measured at $150 \mathrm{~K}$ in Fig. 1(b) consists of two well resolved peaks at 1.21 and $1.27 \mathrm{eV}$. The weak shoulder peak at $1.12 \mathrm{eV}$, which is about $90 \mathrm{meV}$ below the $1.21 \mathrm{eV}$ peak, is the $\mathrm{LO}$ phonon replica of the higher peak.

Based on the energy peak position, the $1.23 \mathrm{eV}$ emission line in GaN may either be a band-to-impurity or a DAP transition. We measured the excitation intensity $\left(\mathrm{I}_{\text {exc }}\right)$ dependent PL spectra of this line. Figure 2(a) shows that the peak energy position stayed the same over two orders of magnitude variation in $\mathrm{I}_{\mathrm{exc}}$. This indicates that the $1.23 \mathrm{eV}$ band is a band-to-impurity type because the peak position of a DAP transition typically changes with $\mathrm{I}_{\mathrm{exc}}$ since it is well known that the mean distance between DAPs and hence the emission wavelength decrease with $\mathrm{I}_{\mathrm{exc}}{ }^{24}$ Peak emission intensity, $\mathrm{I}_{\mathrm{emi}}$, at $1.23 \mathrm{eV}$ as a function of $\mathrm{I}_{\mathrm{exc}}$ is plotted in Fig. 2(b), where the solid squares denote the measured data. The solid line is the least square fit of the data with the equation of $\mathrm{I}_{\mathrm{emi}}=\mathrm{aI}_{\mathrm{exc}}^{\beta}$, where $\beta$ is the fitting parameter, which was found to be 0.36 .

Room temperature PL spectra of the GaN epilayer in the visible region are shown in Fig. 3. The spectra consists of sharp and strong emission centered at $3.42 \mathrm{eV}$ due to the band-to-band transition, ${ }^{25}$ as well as impurity transitions. The peak intensity of the band-edge related transition is more than 20 times stronger than that of impurity related transitions at $300 \mathrm{~K}$, which reflects the high optical quality of the sample. The impurity part of the spectrum mainly shows two broad bands. The one centered around $2.85 \mathrm{eV}$ is very weak and was previously identified as the blue luminescence band in GaN. ${ }^{6}$ Like the IR PL spectrum shown in Fig. 1(b), we also observed two separate, clearly resolved emission lines within the single YL band. From fitting, the peak positions of the two lines are at 2.13 and $2.30 \mathrm{eV}$. The energy difference between these two lines $(0.17 \mathrm{eV})$ is close to the difference between the binding energies of $\left(\mathrm{V}_{\mathrm{Ga}}-\mathrm{O}_{\mathrm{N}}\right)^{2-/ 1-}$ for $\mathrm{O}$ replacing $\mathrm{N}$ from $\pi$ - or $\sigma$-bonds $(\sim 0.16 \mathrm{eV}){ }^{26}$ Because of the stable wurtzite structure of $\mathrm{GaN}$, two types of $\mathrm{Ga}-\mathrm{N}$ bonds are distinguished: a longer single bond along the c-axis ( $\pi$-bond) and three equivalent shorter bonds which make a very small angle with the basal plane ( $\sigma$-bond). These bonds

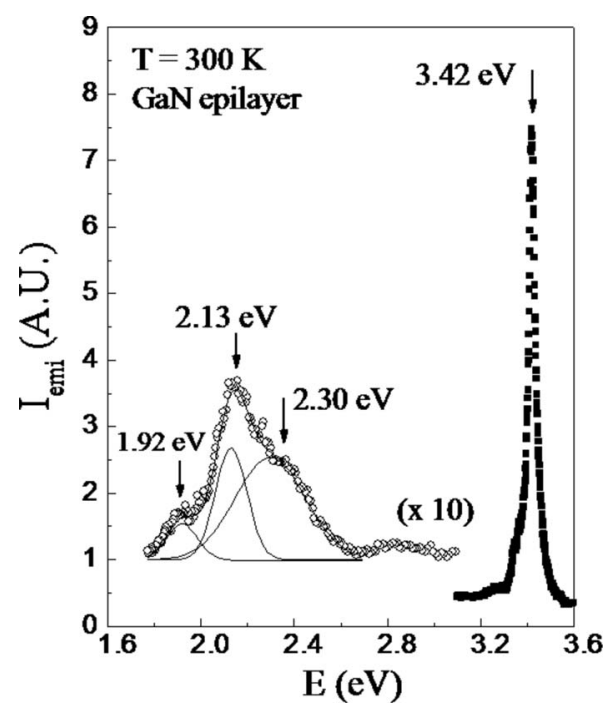

FIG. 3. Room temperature PL spectra of unintentionally doped n-GaN epilayer in UV and visible spectral regions.

are about $1.9550 \AA$ and $1.9486 \AA$, respectively. ${ }^{26}$ Consequently, even with the same charge state, two geometries of the $\left(\mathrm{V}_{\mathrm{Ga}}-\mathrm{O}_{\mathrm{N}}\right)^{2-11-}$ complex are possible. The oxygen atom may substitute the nitrogen from either the $\pi$ - or $\sigma$-bond as illustrated in Fig. 4(a). Corresponding to those two configurations, $\left(\mathrm{V}_{\mathrm{Ga}}-\mathrm{O}_{\mathrm{N}}\right)^{2-/ 1-}$ possesses binding energies of different magnitudes, which offers two fine structures rather than a single level in the gap, giving rise to two emission lines. Relatively stronger intensity at the $2.13 \mathrm{eV}$ branch indicates the availability of a higher population of $\sigma$-type complexes, which may be due to their larger binding energy $(-2.01 \mathrm{eV}$ for $\sigma$-bond versus $-1.85 \mathrm{eV}$ for $\pi$-bond), ${ }^{22}$ and higher degeneracy. Several narrower peaks within the YL band with linewidths in the order of $0.1 \mathrm{eV}$ were previously seen and are attributed to carrier-phonon interaction. ${ }^{27}$ In most cases, these two lines are not well resolved due to broad linewidth.
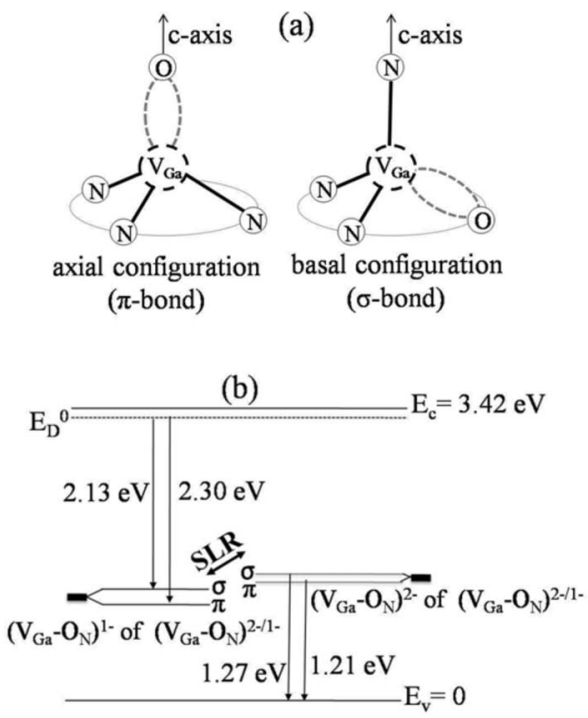

FIG. 4. (a) Atomic geometries of the $\left(\mathrm{V}_{\mathrm{Ga}}-\mathrm{O}_{\mathrm{N}}\right)^{2-/ 1-}$ complex in $\mathrm{GaN}$ for oxygen replacing the nitrogen from (a) $\pi$-bonding (along c-axis) and (b) $\sigma$-bonding (one of the other three equivalent positions). (b) Energy level diagram of $\mathrm{GaN}$ including the charge states $\left(\mathrm{V}_{\mathrm{Ga}}-\mathrm{O}_{\mathrm{N}}\right)^{2-}$ and $\left(\mathrm{V}_{\mathrm{Ga}}-\mathrm{O}_{\mathrm{N}}\right)^{1-}$ of $\left(\mathrm{V}_{\mathrm{Ga}}-\mathrm{O}_{\mathrm{N}}\right)^{2-/ 1-}$ center. SLR stands for small lattice relaxation. 
The sum of the emission energies of the two lines in the YL band (2.13 and $2.30 \mathrm{eV})$ and the corresponding lines in the freshly observed IR band $(1.27$ and $1.21 \mathrm{eV})$ shown in Fig. 1 are close to the energy gap of GaN. We suggest that the origin of the YL and IR bands share a common defect center in the gap. The involvement of the gallium vacancy complex $\left(\mathrm{V}_{\mathrm{Ga}}-\mathrm{O}_{\mathrm{N}}\right)^{2-11-}$ in the $\mathrm{YL}$ band is a well established fact and the electronic level of $\left(\mathrm{V}_{\mathrm{Ga}}-\mathrm{O}_{\mathrm{N}}\right)^{2-11-}$ has been reported to be around 1.1-1.3 eV (Refs. 21 and 27) from top of the VB. Therefore, we propose that the observed IR band is due to recombination between electrons in the $\left(\mathrm{V}_{\mathrm{Ga}}-\mathrm{O}_{\mathrm{N}}\right)^{2-}$ charge state of $\left(\mathrm{V}_{\mathrm{Ga}}-\mathrm{O}_{\mathrm{N}}\right)^{2-11-}$ and holes in the VB. $\mathrm{I}_{\text {exc }}$-dependent PL in Fig. 2 also supports the assignment that the IR band originates from a band-to-impurity type transition.

Figure 4(b) plots the energy levels for $\mathrm{GaN}$ at $300 \mathrm{~K}$, featuring the shallow donor level $\left(\mathrm{E}_{\mathrm{D}}{ }^{0}\right)$ and the deep acceptor levels resulting from two charge states $\left(\mathrm{V}_{\mathrm{Ga}}-\mathrm{O}_{\mathrm{N}}\right)^{2-}$ and $\left(\mathrm{V}_{\mathrm{Ga}}-\mathrm{O}_{\mathrm{N}}\right)^{1-}$ of the gallium vacancy-oxygen impurity complex $\left(\mathrm{V}_{\mathrm{Ga}}-\mathrm{O}_{\mathrm{N}}\right)^{2-11-}$. The energy level due to each charge state is further split into two fine structures due to $\mathrm{Ga}-\mathrm{N}$ bond anisotropy. These structures are denoted by the $\pi$ and $\sigma$ configurations as shown in Fig. 4(a). The suggested mechanism of the two lines in the YL band $(2.13$ and $2.30 \mathrm{eV})$ can be described by the following equations:

$$
\mathrm{D}^{0}+\left(\mathrm{V}_{\mathrm{Ga}}-\mathrm{O}_{\mathrm{N}}^{\sigma}\right)^{1-}=\mathrm{D}^{+}+\left(\mathrm{V}_{\mathrm{Ga}}-\mathrm{O}_{\mathrm{N}}^{\sigma}\right)^{2-}+\mathrm{h} \nu(2.13 \mathrm{eV}),
$$

$$
\mathrm{D}^{0}+\left(\mathrm{V}_{\mathrm{Ga}}-\mathrm{O}_{\mathrm{N}}^{\pi}\right)^{1-}=\mathrm{D}^{+}+\left(\mathrm{V}_{\mathrm{Ga}}-\mathrm{O}_{\mathrm{N}}^{\pi}\right)^{2-}+\mathrm{h} \nu(2.30 \mathrm{eV}),
$$

where $\mathrm{D}^{0}$ and $\mathrm{D}^{+}$denote shallow donors in the neutral and charged states, respectively. However, for the IR transitions $(1.27$ and $1.21 \mathrm{eV})$ to occur, we must have a significant population in the charge state of $\left(\mathrm{V}_{\mathrm{Ga}}-\mathrm{O}_{\mathrm{N}}\right)^{2-}$. Partial filling of the defect state $\left(\mathrm{V}_{\mathrm{Ga}}-\mathrm{O}_{\mathrm{N}}\right)^{2-/ 1-}$ during PL emission as illustrated in Eqs. (1) and (2) changes its charge state from $\left(\mathrm{V}_{\mathrm{Ga}}-\mathrm{O}_{\mathrm{N}}\right)^{1-}$ to $\left(\mathrm{V}_{\mathrm{Ga}}-\mathrm{O}_{\mathrm{N}}\right)^{2-}$. Consequently, the surrounding $\mathrm{N}$ and $\mathrm{O}_{\mathrm{N}}$ atoms move inward ${ }^{8,28}$ and gain some energy as shown in Fig. 4(b). ${ }^{8}$ Now the available $\left(\mathrm{V}_{\mathrm{Ga}}-\mathrm{O}_{\mathrm{N}}\right)^{2-}$ state can participate in the electron transition to the $\mathrm{VB}$, giving 1.27 and $1.21 \mathrm{eV}$ PL emissions as described by the following:

$$
\begin{aligned}
& \left(\mathrm{V}_{\mathrm{Ga}}-\mathrm{O}_{\mathrm{N}}^{\sigma}\right)^{2-}+\mathrm{h}^{+}=\left(\mathrm{V}_{\mathrm{Ga}}-\mathrm{O}_{\mathrm{N}}^{\sigma}\right)^{1-}+\mathrm{h} \nu(1.27 \mathrm{eV}), \\
& \left(\mathrm{V}_{\mathrm{Ga}}-\mathrm{O}_{\mathrm{N}}^{\pi}\right)^{2-}+\mathrm{h}^{+}=\left(\mathrm{V}_{\mathrm{Ga}}-\mathrm{O}_{\mathrm{N}}^{\pi}\right)^{1-}+\mathrm{h} \nu(1.21 \mathrm{eV}) .
\end{aligned}
$$

In summary, high quality $\mathrm{GaN}$ epilayers were synthesized by MOCVD for studying the fundamental properties of deep center emissions. We observed an IR emission band with a peak at $1.23 \mathrm{eV}$ due to the transition from $\left(\mathrm{V}_{\mathrm{Ga}}-\mathrm{O}_{\mathrm{N}}\right)^{2-}$ charge state of $\left(\mathrm{V}_{\mathrm{Ga}}-\mathrm{O}_{\mathrm{N}}\right)^{2-/ 1-}$ center to the VB. At lower temperatures $(150 \mathrm{~K})$, the IR band resolved into two lines, which correlate well with the two separate lines resolved within the YL band. Our results provide explicit evidence that both the YL band and the $1.23 \mathrm{eV}$ line in $\mathrm{GaN}$ emission spectra are related to a common deep center, which is believed to be $\left(\mathrm{V}_{\mathrm{Ga}}-\mathrm{O}_{\mathrm{N}}\right)^{2-1-}$.

This work is supported by DOE under Grant No. FG0209ER46552. H. X. Jiang and J. Y. Lin would like to acknowledge the support of Whitacre endowed chair positions through the AT\&T foundation.

${ }^{1}$ S. Nakamura and G. Fasol, The Blue Laser Diode: GaN Based Light Emitters and Lasers (Springer, Berlin, 1997).

${ }^{2}$ J. I. Pankove and J. A. Hutchby, J. Appl. Phys. 47, 5387 (1976).

${ }^{3}$ G. D. Chen, M. Smith, J. Y. Lin, H. X. Jiang, S. H. Wei, M. A. Khan, and C. J. Sun, Appl. Phys. Lett. 68, 2784 (1996).

${ }^{4}$ S. Nagahama, N. Iwasa, M. Senoh, T. Matsushita, Y. Sugimoto, H. Kiyoku, T. Kozaki, M. Sano, H. Matsumura, H. Umemoto, K. Chocho, T. Yanamoto, and T. Mukai, Phys. Status Solidi A 188, 1 (2001).

${ }^{5}$ L. Liu and J. H. Edgar, Mater. Sci. Eng. R. 37, 61 (2002).

${ }^{6}$ M. A. Reshchikov and H. Morkoç, J. Appl. Phys. 97, 061301 (2005).

${ }^{7}$ T. Ogino and M. Aoki, Jpn. J. Appl. Phys., Part 1 19, 2395 (1980).

${ }^{8}$ T. Mattila and R. M. Nieminen, Phys. Rev. B 55, 9571 (1997).

${ }^{9}$ S. Limpijumnong and C. G. Van de Walle, Phys. Rev. B 69, 035207 (2004).

${ }^{10}$ I. Gorczyca, N. E. Christensen, and A. Svane, Phys. Rev. B 66, 075210 (2002)

${ }^{11}$ K. Saarinen, T. Laine, S. Kuisma, J. Nissilä, P. Hautojärvi, L. Dobrzynski, J. M. Baranowski, K. Pakula, R. Stepniewski, M. Wojdak, A. Wysmolek, T. Suski, M. Leszczynski, I. Grzegory, and S. Porowski, Phys. Rev. Lett. 79, 3030 (1997).

${ }^{12}$ J. Oila, V. Ranki, J. Kivioja, K. Saarinen, P. Hautojärvi, J. Likonen, J. M. Baranowski, K. Pakula, T. Suski, M. Leszczynski, and I. Grzegory, Phys. Rev. B 63, 045205 (2001).

${ }^{13}$ A. Uedono, S. F. Chichibu, Z. Q. Chen, M. Sumiya, R. Suzuki, T. Ohdaira, and T. Mikado, J. Appl. Phys. 90, 181 (2001).

${ }^{14}$ K. Saarinen, V. Ranki, T. Suski, M. Bockowski, and I. Grzegory, J. Cryst. Growth 246, 281 (2002).

${ }^{15}$ K. B. Nam, M. L. Nakarmi, J. Y. Lin, and H. X. Jiang, Appl. Phys. Lett. 86, 222108 (2005).

${ }^{16}$ N. Nepal, M. L. Nakarmi, J. Y. Lin, and H. X. Jiang, Appl. Phys. Lett. 89, 092107 (2006).

${ }^{17}$ W. Götz, N. M. Johnson, R. A. Street, H. Amano, and I. Akasaki, Appl. Phys. Lett. 66, 1340 (1995).

${ }^{18}$ G. C. Yi and B. W. Wessels, Appl. Phys. Lett. 68, 3769 (1996).

${ }^{19}$ I. Shalish, L. Kronik, G. Segal, Y. Rosenwaks, Y. Shapira, U. Tisch, and J. Salzman, Phys. Rev. B 59, 9748 (1999).

${ }^{20}$ R. Y. Korotkov, J. M. Gregie, and B. W. Wessels, GaN and Related Alloys, MRS Symposia Proceedings No. 639 (Materials Research Society, Pittsburgh, 2000), p. G3.7.

${ }^{21} \mathrm{http}: / / \mathrm{www} 2 . e c e . t t u . e d u /$ nanophotonics/.

${ }^{22}$ J. Neugebauer and C. G. Van de Walle, Appl. Phys. Lett. 69, 503 (1996).

${ }^{23}$ J. Jenny, R. Jones, J. E. Van Nostrand, D. C. Reynolds, D. C. Look, and B. Jogai, Solid State Commun. 106, 701 (1998).

${ }^{24}$ D. G. Thomas, J. J. Hopfield, and W. M. Augustyniak, Phys. Rev. 140, A202 (1965).

${ }^{25}$ M. Smith, J. Y. Lin, H. X. Jiang, and M. A. Khan, Appl. Phys. Lett. 71, 635 (1997).

${ }^{26}$ K. Lawniczak-Jablonska, T. Suski, I. Gorczyca, N. E. Christensen, K. E. Attenkofer, R. C. C. Perera, E. M. Gullikson, J. H. Underwood, D. L. Ederer, and Z. L. Weber, Phys. Rev. B 61, 16623 (2000).

${ }^{27}$ J. S. Colton, P. Y. Yu, K. L. Teo, E. R. Weber, P. Perlin, I. Grzegory, and K. Uchida, Appl. Phys. Lett. 75, 3273 (1999).

${ }^{28}$ J. Neugebauer and C. G. Van de Walle, Phys. Rev. B 50, 8067 (1994). 